\title{
ANÁLISE HIDROGEOQUÍMICA NO MUNICÍPIO DE CURITIBA - PR
}

\author{
HYDROGEOCHEMISTRY IN CURITIBA-PR
}

\author{
Camila de Vasconcelos Müller ${ }^{1}$, Gustavo Barbosa Athayde ${ }^{1}$, Ernani Francisco da Rosa Filho², André Vir- \\ mond Lima Bittencourt ${ }^{3}$, Luiz Eduardo Mantovani ${ }^{2}$ e Eduardo Chemas Hindi ${ }^{2}$
}

\begin{abstract}
RESUMO O estudo hidrogeoquímico determinou em escala de 1:300.000, a tipologia da água subterrânea do Município de Curitiba- PR, relacionando-as com influências urbanas, tipo litológico e bacias hidrográficas. O tipo bicarbonatada cálcica é o predominante e, as concentrações relativamente elevadas do cátion cálcio são observadas próximo da Zona de Falha do Passaúna, Bacias hidrográficas dos rios Belém e Barigui, em poços construídos sobre os sedimentos da Formação Guabirotuba. A recarga natural ocorre principalmente com a infiltração da chuva nos sedimentos da Formação Guabirotuba e, permite a substituição do cátion cálcio pelo sódio, marcando o segundo tipo predominante nas águas, tipo bicarbonatada sódica. As águas bicarbonatadas que tendem para cloretadas representam cerca de 3\% do total de 227 análises físico-químicas e, ocorrem principalmente na região mais antiga de Curitiba, na Regional da Matriz. Nesta região o íon cloreto associa-se ao nitrato e, esta interação reflete a influência do ambiente urbano na qualidade das águas subterrâneas, uma vez que a presença destes elementos na área caracteriza a contaminação por efluentes domésticos. A não potabilidade de algumas águas em Curitiba, visto que existe próximo de 1000 (um mil) poços tubulares na cidade, cria um grave problema municipal, por isso é necessário um monitoramento e a quantificação da qualidade da água.
\end{abstract}

Palavras-chave: Aqüífero urbano; Complexo Atuba; Formação Guabirotuba; hidrogeoquímica; avaliação.

\begin{abstract}
Water demand for Curitiba population exceeds $4 \mathrm{~m}^{3} / \mathrm{s}$. This demand are for services stations in general as hospitals, shoppings, clubs, restaurants, schools, parks, hotels, motels, plants and industries. Part of this demand are supplied by 1500 groundwater wells in Curitiba city. Curitiba have two aquifers: a sedimentary, represented for Fm. Guabirotuba and alluviums deposits and, a crystalline/fractured one, represented by Atuba Complex. Using 227 physical-chemistries water analyses, accepted $5 \%$ of DBI, five water types were determinated: bicarbonated calcium, bicarbonated magnesium, bicarbonates sodium, bicarbonated cloride mixing and cloride-bicarbonated mixing. Total solids dissolved (TSD), $\mathrm{SiO}_{2}^{-}, \mathrm{HCO}_{3}^{-}$ $, \mathrm{Cl}^{-}, \mathrm{SO}_{4}{ }^{2-}, \mathrm{Mg}^{+2}$,color, specific conductance and alkalinity concentrations increase in wells perforateed at alluviums sites. Concentrations of $\mathrm{PO}_{4}^{3-}, \mathrm{NO}_{3}^{-}, \mathrm{Na}^{+}$, hardness and acidity raised in the wells perforateed at Fm. Guabirotuba. Wells situated on Atuba Complex have the lowest average physical-chemistries concentrations. A multivariate statistical analysis, here, Principal Components Analysis and Factor Analysis, was applied in 166 analyses physical-chemistries, being enough to explain more than $73 \%$ of total variation of the system. Most of studied wells parameters not exceed the maximum reference law limits, Ordinance $\mathrm{n}^{\circ} 518$ of the Health department. Some wells parametres, mainly at Regional Matriz, are above when compare whith referencial limits. A new site campaign, sampling water to evaluate the current quality parameters is necessarie to management this resource.
\end{abstract}

Keywords: Urban Aquifer, Atuba Complex, Guabirotuba Formation, hydrogeochemistry

\section{INTRODUÇÃO}

A área de estudo abrange todo o município de Curitiba-PR (Figura 1), com superfície de 436 $\mathrm{km}^{2}$, localiza-se no Primeiro Planalto Paranaense, limitado a leste pelas escarpas da Serra do Mar e a oeste pelo Segundo Planalto Paranaense, denominado de Campos Gerais. Segundo a divisão regional adotada pela Secretaria Municipal de Meio Ambiente de Curitiba - SMMA, o município é dividido em 8 unidades regionais: Bairro Novo,
Boa Vista, Boqueirão, Cajuru, Matriz, Pinheirinho, Portão, Santa Felicidade.

Parte da demanda hídrica do Município de Curitiba, utilizada para abastecer condomínios e postos de serviço em geral, é suprida por aproximadamente 1500 poços tubulares profundos particulares, que podem perfurar os sedimentos quaternários, terciários, rochas mesozóicas e as rochas do Complexo Atuba.

\footnotetext{
${ }^{1}$ UFPR - alunos da Pós-graduação em Geologia (camilavmuller@yahoo.com.br)e (gustavo_athayde@yahoo.com.br).

${ }^{2}$ LPH - Laboratório de Pesquisas Hidrogeológicas - Depto. de Geologia - Universidade Federal do Paraná (ernani@ufpr. br), (lem@ufpr.br)e(hindi@ufpr.br).

${ }^{3}$ LPH Degeol-UFPR / UNICEMP - Centro Universitário Positivo (andré@ufpr.br).
} 


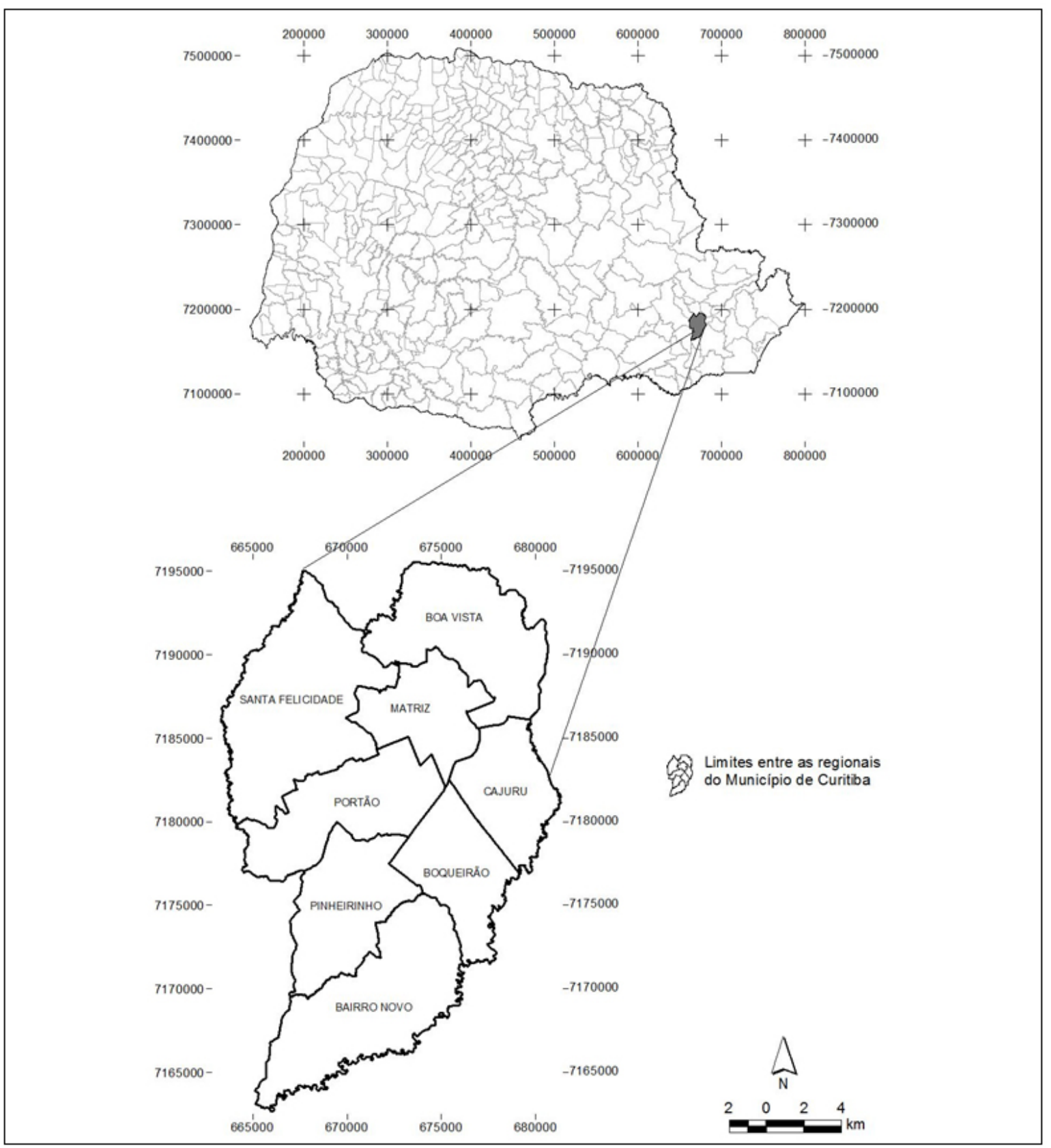

Figura 1- Localização do município de Curitiba no estado do Paraná (modificado de SMMA).

Figure 1-Localization maps of the study area.

A magnitude da recarga da água subterrânea depende das condições que são impostas pelas formas de uso e ocupação do território. Os processos de infiltração e recarga dos aqüíferos são dificultados pelo crescimento urbano e impermeabilização do solo nas cidades.

Algumas análises físico-químicas, de águas coletadas em poços tubulares profundos para fins de abastecimento privado em Curitiba, apresentaram concentrações dos parâmetros $\mathrm{F}^{-}, \mathrm{NO}_{3}^{-}$, ferro total, $\mathrm{pH}$, cor e turbidez acima dos padrões de potabilidade estabelecidos pela Portaria n ${ }^{\circ}$ 518/94
(BRASIL, 1994). Esses valores elevados podem ser indícios de infiltração de águas superficiais de baixa qualidade, provenientes da rede de drenagem, atividades antrópicas ou de possíveis vazamentos na rede de esgoto.

Os poços tubulares profundos situados nas imediações destes locais devem ser monitorados com maior freqüência, buscando identificar possíveis alterações na qualidade das águas.

Os métodos utilizados neste trabalho ignoram a variação de profundidade dos poços, sendo assim, os resultados correspondem à interpretação da 
composição química média das águas dos poços e da geologia local.

O principal motivo para a adoção deste procedimento deve-se ao grande número de filtros dispostos ao longo dos poços, fazendo com que ocorra a mistura das águas dos diversos níveis sobre a água coletada na boca do poço.

\section{Objetivos}

Os objetivos principais deste trabalho são:

1. Classificação da água subterrânea com base em análises físico-químicas de poços perfurados no município de Curitiba.

2. Relação entre concentrações físicoquímicas versus litotipo aflorante.

3. Análise estatística multivariada para avaliar presença de anomalias nos parâmetros físico-químicos que possam degradar a qualidade da água.

\section{Materiais e Métodos}

$\mathrm{Na}$ confecção do banco de dados, foram catalogados e georreferenciadas 227 análises físico-químicas, sendo que 91 laudos analíticos provenientes do acervo de análises físico-químicas do Laboratório de Pesquisas Hidrogeológicas (LPH - UFPR); 45 análises físico-químicas de Nogueira (1997) e 91 análises compiladas dos bancos de dados da Superintendência de Recursos Hídricos e Saneamento Ambiental (SUDERHSA) e do Geólogo Marcelus Vinicius Klinguelfus Borges.

Também foram utilizadas Informações adicionais de dados de vazão, nível estático, nível dinâmico e profundidade dos poços de 131 poços outorgados obtidos no mapa da extinta SUREHMA (1989).

A consistência e qualidade dos dados foram avaliadas com base na Diferença de Balanço Iônico (DBI), aceitando-se diferenças de até 5\%.

Os tipos de água foram determinados com base na presença de mais de $50 \%$ dos compostos químicos, sendo que nas águas onde os compostos químicos não atingiram $50 \%$, a tipologia foi denominada pelos compostos que apresentaram as duas maiores porcentagens, respectivamente.

O diagrama triangular de Piper (1944) foi utilizado para classificar e representar graficamente o tipo químico da água subterrânea, de acordo com a espécie predominante, e também, para definir a evolução química das águas.
Foram utilizadas técnicas de estatística multivariada como a Análise de Componentes Principais (PCA), visando resumir o comportamento de um processo descrito por dezenas de variáveis em um número muito menor de variáveis, reduzindo a ordem de um problema e determinando um número menor de variáveis que descreve um determinado conjunto de dados (SEIXAS FILHO et al., 2006).

Para concluir sobre a contribuição de uma variável na variabilidade geral do sistema, todas as variáveis foram normalizadas para média $0 \mathrm{e}$ variância 1. Isso evita que variáveis que tenham uma grande magnitude em relação às demais, devido à diferença de escala ou unidade, possam dar a aparência de que contribuem muito para a variabilidade total do sistema.

A análise multivariada visou identificar grupos semelhantes e confrontá-los com o contexto geológico e bacia hidrográfica local.

Após as etapas citadas, pôde-se integrar os dados físico-químicos, a rede hidrográfica e as informações geológicas em um sistema de informações geográficas (SIG).

\section{Contexto Geológico}

A região de Curitiba esta situada sobre distintas unidades litoestratigráficas (Tabela 1), sendo que as unidades de maior área de ocorrência são os depósitos aluvionares, sedimentos da Formação Guabirotuba e o Complexo Atuba.

\section{Complexo Atuba}

Para Siga Jr. (1995), o Domínio Curitiba constitui uma faixa alongada e estreita, de direção NE-SW, cujo embasamento seria representado por gnaisses bandados, gnaisses graníticos e migmatitos denominados de Complexo Atuba.

O padrão estrutural como um todo é resultado de uma tectônica essencialmente cisalhante, com transporte relativo para sul-sudeste. Os migmatitos do Complexo Atuba, segundo Siga Jr. et al. (1995), foram gerados no Paleoproterozóico $(2000 \pm 200$ Ma) e remigmatizados no Neoproterozóico (600 $\pm 20 \mathrm{Ma})$. Trata-se de uma unidade gerada em ambiente profundo, com metamorfismo na fácies anfibolito, acrescida à borda do Domínio Luís Alves durante o Neoproterozóico, decorrente de processos globais que envolveram aglutinações de massas continentais. 
Tabela 1- Coluna estratigráfica da Bacia de Curitiba (SALAMUNI, 2005).

Table 1 - Stratigrafic chart of Curitiba Basin (SALAMUNI, 2005).

\begin{tabular}{|c|c|c|}
\hline IDADE & $\begin{array}{l}\text { UNIDADE } \\
\text { GEOLÓGICA }\end{array}$ & LITOLOGIA PRINCIPAL \\
\hline $\begin{array}{l}\text { Quaternário (superior) } \\
\text { Holoceno }\end{array}$ & $\begin{array}{l}\text { Aluviões e depósitos } \\
\text { Coluvionares } \\
\text { secundários }\end{array}$ & $\begin{array}{l}\text { Depósitos arenosos pouco selecionados a } \\
\text { selecionados, friáveis e em parte com matriz } \\
\text { argilosa }\end{array}$ \\
\hline $\begin{array}{l}\text { Quaternário (inferior) } \\
\text { Pleistoceno a Holoceno }\end{array}$ & Formação Tinguis & $\begin{array}{c}\text { Colúvios argilosos, cascalheiras e lentes } \\
\text { de areias arcosianas (Fm. Guabirotuba } \\
\text { retrabalhada) }\end{array}$ \\
\hline $\begin{array}{l}\text { Terceário (médio a } \\
\text { superior) Oligomioceno } \\
\text { - Mioceno a Plioceno }\end{array}$ & Formação Guabirotuba & $\begin{array}{c}\text { Argilitos, arenitos arcosianos, conglomerados } \\
\text { com matriz areno-argilosa, lentes de arenitos } \\
\text { quartzosos e depósitos carbonáticos restritos } \\
\text { (calcretes e caliches) }\end{array}$ \\
\hline Jurássico- Cretáceo & Formação Serra Geral & Diques de diabásio e dioritos (lamprófiros) \\
\hline $\begin{array}{c}\text { Proterozóico superior a } \\
\text { Cambriano } \\
\end{array}$ & $\begin{array}{l}\text { Maciços graníticos da } \\
\text { Serra do Mar } \\
\end{array}$ & Granitos alcalinos \\
\hline Proterozóico superior & $\begin{array}{l}\text { Grupo Açungui } \\
\text { (Formação Capirú) }\end{array}$ & $\begin{array}{l}\text { Quartzitos, filitos, mármores dolomíticos e } \\
\text { calcíticos }\end{array}$ \\
\hline $\begin{array}{l}\text { Proterozóico inferior a } \\
\text { arqueano }\end{array}$ & $\begin{array}{l}\text { Complexo Atuba } \\
\text { (antigo Complexo } \\
\text { Costeiro) } \\
\end{array}$ & $\begin{array}{l}\text { Migmatitos, ortognaisse, xistos, quartzitos } \\
\text { restritos e granitos orogênicos deformados }\end{array}$ \\
\hline
\end{tabular}

Salamuni (2005) descreve para o Complexo Atuba, uma paragênese de grau metamórfico médio a alto, com cristalização da granada, hornblenda e biotita, gerada por tectônica tangencial de baixo a médio ângulo, a qual produziu imbricamento tectônico, dobras de cisalhamento, gnaissificação e migmatização.

Superimpostoaosreferidosconjuntosocorreram eventos de tectônica rúptil que são caracterizados através de famílias de fraturas com direções N-S, NW-SE e NE-SW, presentes por toda a área em escalas locais a regionais (SALAMUNI, 2005).

Salamuni (2005) supõe idade pós-cretácea para os eventos rúpteis apontando que o movimento dos blocos estruturais condicionou morfoestruturas, tais como escarpas de falha, erosão de parte dos sedimentos da bacia de Curitiba e o controle das manchas de sedimentos da Formação Guabirotuba.

\section{Formação Guabirotuba}

Esta formação encontra-se de forma discordante sobre as rochas do Complexo Atuba, recoberta pelos sedimentos da Formação Tinguis, de origem pleistocênica a holocênica, constituída por sedimentos retrabalhados da própria Formação Guabirotuba; e por depósitos aluvionares recentes dos afluentes das Bacias Hidrográficas do Rio Iguaçu.

A Formação Guabirotuba é composta predominantementeporargilas esiltes esverdeados, que gradam para sedimentos mais grossos nas bordas da bacia (BIGARELLA; SALAMUNI, 1959,BECKER, 1982,SALAMUNI;SALAMUNI; EBERTH, 1999).

Muitas vezes os sedimentos mais grossos estão sobre os sedimentos mais finos devido ao deslocamento dos meandros primitivos dos rios, o que acarretou em uma variedade na orientação e volume dos depósitos.

A Formação foi depositada durante o Pleistoceno Superior, em ambiente de leques aluvionares coalescentes, caracterizada por amplos vales de canais anastomosados, apresentando uma espessura máxima de $80 \mathrm{~m}$ na porção central da bacia de Curitiba (BIGARELLA; SALAMUNI, 1959).

\section{Contexto Hidrogeológico}

Os sistemas aqüíferos do Município de Curitiba podem ser classificados em três grupos distintos, de acordo com a natureza litológica e propriedades hidráulicas:

- Sistemas Aqüíferos sedimentares, representados pela Formação Guabirotuba e depósitos aluvionares.

- Sistema Aqüífero cristalino, representado pelo Complexo Atuba.

- Sistema Aqǘfero cárstico, representado pela Formação Capirú.

São de interesse deste estudo apenas os aqǘferos sedimentares e cristalinos, presentes na 
área.

\section{Complexo Atuba}

O Complexo Atuba é um aqüífero do tipo secundário no qual o armazenamento e fluxo da água estão associados às feições geo-estruturais, como falhas e diáclases.

Segundo Chavez-Kus (2003), a média da profundidade dos poços tubulares profundos é 112 $\mathrm{m}$ e a mediana da entrada de água é de $84 \mathrm{~m}$, sendo que no primeiro quartil tem-se $60 \mathrm{~m}$ e no terceiro quartil tem-se $115 \mathrm{~m}$. As entradas de água podem ocorrer através de fraturas conectadas às porções saturadas da cobertura de solo ou da Formação Guabirotuba.

No aqüífero cristalino (Complexo Atuba), a variação dos teores de sólidos totais dissolvidos está entre $100 \mathrm{mg} / \mathrm{L}$ e $150 \mathrm{mg} / \mathrm{L}, \mathrm{pH}$ entre 6,5 e 7 e dureza inferior a $100 \mathrm{mg} / \mathrm{L}$ de $\mathrm{CaCO}_{3}$. Entre os cátions, predominam o cálcio (2 a $20 \mathrm{mg} / \mathrm{L})$ e o magnésio $(0,5$ a $12 \mathrm{mg} / \mathrm{L})$ em relação ao sódio (1 a $3 \mathrm{mg} / \mathrm{L})$ e ao potássio (1 a $2 \mathrm{mg} / \mathrm{L})(\mathrm{ROSA}$ FILHO; HINDI; LUCENA, 2002).

\section{Formação Guabirotuba}

Trata-se de um aqüífero do tipo primário, no qual o armazenamento e fluxo da água estão associados à porosidade natural das lentes de areias arcosianas. Sob o ponto de vista hidráulico a superfície freática e as águas das chuvas representam a principal fonte de recarga do aqüífero Guabirotuba. (ROSA FILHO; LISBOA; SCHOENAU, 1996).

Rosa Filho et al. (1998a) realizaram investigações nos sedimentos da Formação Guabirotuba, nas imediações do Parque Castelo Branco, no Município de Pinhais, a $15 \mathrm{~km}$ a nordeste de Curitiba. Os autores determinaram que as camadas arenosas, que intercalam os sedimentos pelíticos, apresentam variações quanto a espessura, mas ocorrem de forma relativamente contínua, sendo que estas camadas arenosas, via de regra basais, apresentam espessuras entre $4 \mathrm{e}$ $18 \mathrm{~m}$.

$\mathrm{O}$ aqüífero Guabirotuba é o mais produtivo na região nordeste da cidade de Curitiba, onde as vazões dos poços atingem $80 \mathrm{~m}^{3} / \mathrm{h}$, sendo que na parte da bacia de Curitiba onde as lentes de areias arcosianas são de menor espessura, as vazões médias são restritas a $5 \mathrm{~m}^{3} / \mathrm{h} /$ poço. $\mathrm{O}$ volume disponível de água que pode ser utilizada no sistema de abastecimento público é de $12,6 \times 10^{6}$ $\mathrm{m}^{3} /$ ano (ROSA FILHO et al. 1998b).

Estudos hidroquímicos realizados por Rosa
Filho et al. (1998c), nos sedimentos da Formação Guabirotuba, mostram que as concentrações dos sólidos totais dissolvidos variam entre 90 e 297 $\mathrm{mg} / \mathrm{L}$ e os valores de $\mathrm{pH}$ situam-se entre 6,7 e 8,1 $\mathrm{mg} / \mathrm{L}$.

Os mesmos autores identificaram que os teores de ferro estão entre 0,07 e $1,04 \mathrm{mg} / \mathrm{L}$, as concentrações de sódio variam de 7,1 a $24 \mathrm{mg} / \mathrm{L}$, de cálcio entre 3,83 e $28,4 \mathrm{mg} / \mathrm{L}$, de magnésio entre 1,16 e $28,4 \mathrm{mg} / \mathrm{L}$ e, os teores do potássio não ultrapassam $2,0 \mathrm{mg} / \mathrm{L}$.

\section{RESULTADOS OBTIDOS}

Classificação hidroquímica

Foram classificados cinco tipos principais de águas: Bicarbonatada cálcica (73,5\%); bicarbonatada sódica $(16,7 \%)$, bicarbonatada magnesiana $(6,6 \%)$, bicarbonatada-cloretada $(2,6 \%)$ e cloretada-bicarbonatada magnesianasódica $(0,4 \%)$.

Foi elaborado um diagrama de Piper (1944) para todo o universo amostral (Figura 5) onde são observadas duas tendências evolutivas para as águas.

Primeiramente, as águas com predomínio de $\mathrm{Ca}^{2+}$, evoluem para águas mistas, próximo ao campo do $\mathrm{Mg}^{2+}$ e, secundariamente, as águas cálcicas evoluem para o vértice das águas sódicas.

No campo correspondente aos ânions, observa-se que a evolução das águas parte do vértice do $\mathrm{HCO}_{3}^{-}$em direção ao vértice do $\mathrm{Cl}^{-}$.

No campo dos resultados do Diagrama de Piper, observam-se 2 evoluções para as águas. A primeira é a tendência das águas bicarbonatadas cálcicas e bicarbontadas magnesianas migrarem para o campo corresponde ao tipo de água bicarbonatada sódica. A segunda tendência evolutiva das águas bicarbonatadas cálcicas e bicarbontadas magnesianas é a migração para o campo das águas cloretadas mistas.

As águas do tipo bicarbonatada cloretada e cloretada-bicarbonatada foram determinadas em 7 poços tubulares, localizados na porção norte do município, nas regionais Matriz e Boa Vista, bacias hidrográficas dos rios Belém e Atuba. 


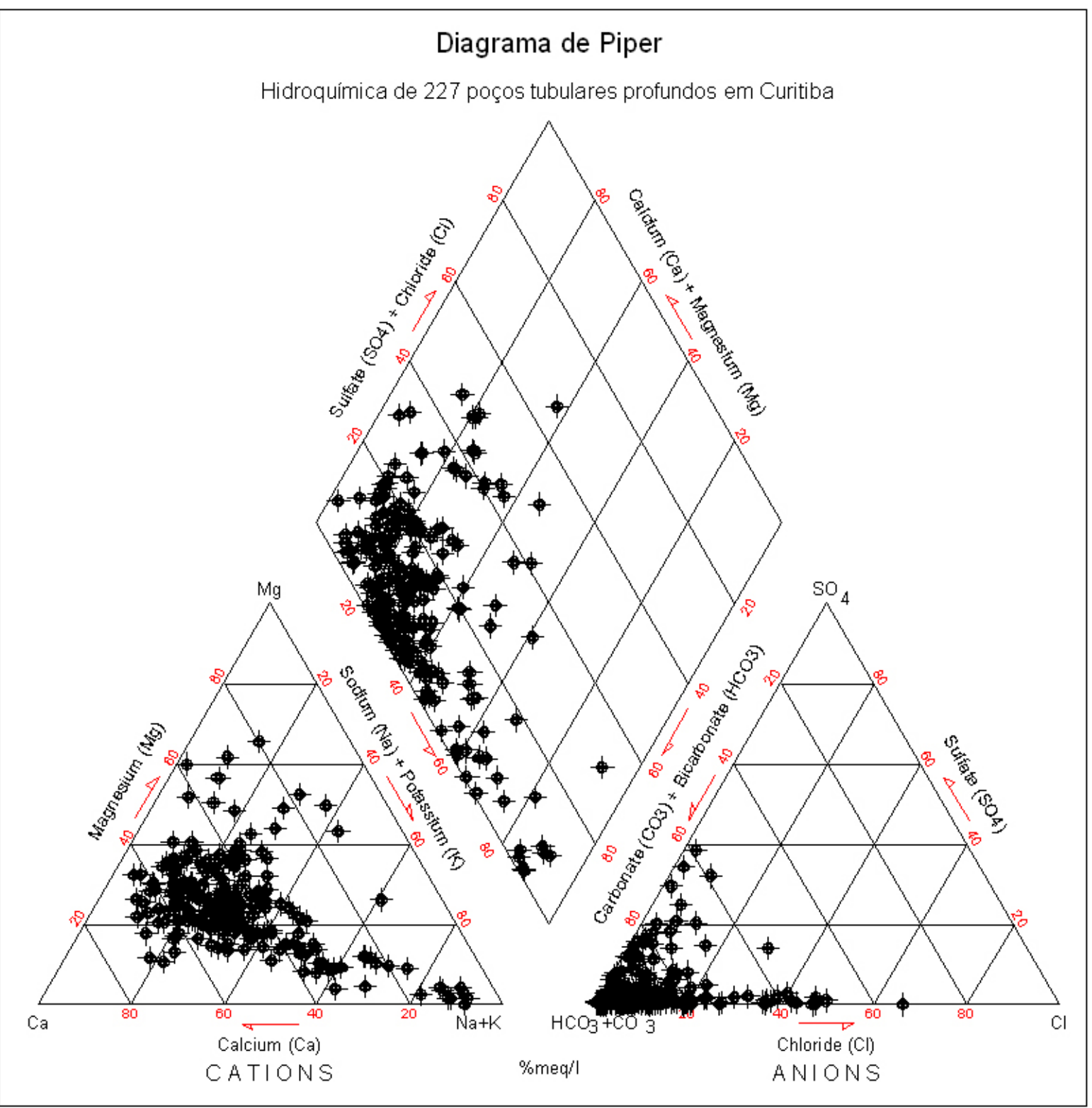

Figura 5 - Diagrama de Piper.

Figure 5-Piper diagram

A predominância de cloretos nas águas, bem como de sulfatos e nitratos, e sua relação com bicarbonatos, indicam provável contaminação causada por efluentes domésticos e/ou industriais (ROSA FILHO et al. 1998c).

As relações $\mathrm{Cl}^{-} \times \mathrm{NO}_{3}^{-}$e $\mathrm{Cl}^{-} \times \mathrm{HCO}_{3}^{-}$, para as águas do tipo bicarbonatada cloretada e cloretada-bicarbonatada, apresentam coeficientes de determinação $\left(\mathrm{R}^{2}\right)$ de 0,87 e 0,80 , respectivamente.

Foi elaborado outro diagrama de Piper (1944) para os valores medianos dos cinco tipos de água (Figura 6), uma tabela (Tabela 2) com as concentrações médias e as medianas e um mapa com a localização espacial dos tipos de águas (Figura 7). 


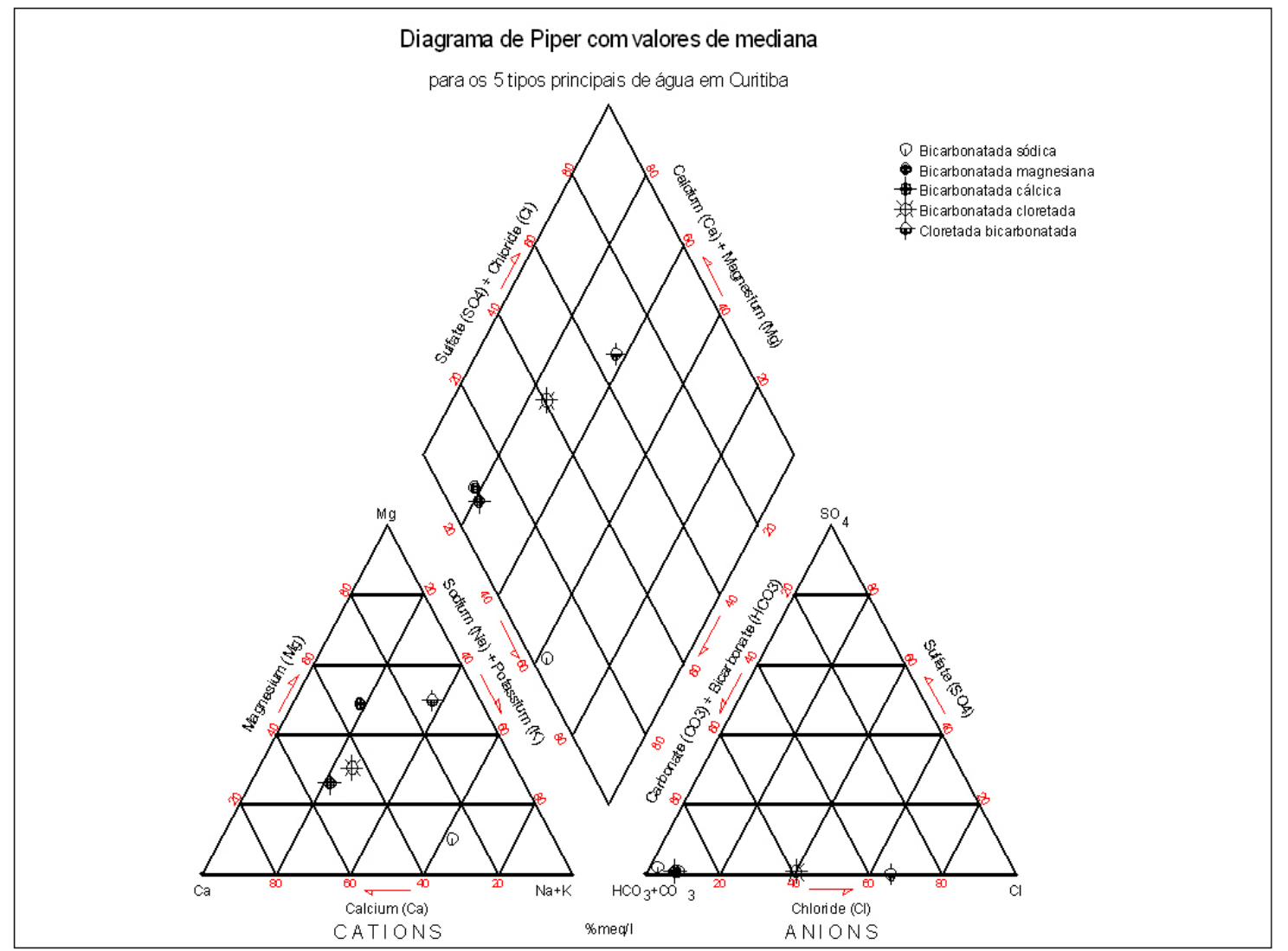

Figura 6- Diagrama de Piper com valores de medianas correspondentes aos 5 principais tipos de águas subterrâneas do Município de Curitiba.

Figure 6- Piper diagram with the 5 main water types in Curitiba city.

\begin{tabular}{|c|c|c|c|c|c|c|c|c|}
\hline \multirow[t]{2}{*}{$\begin{array}{l}\text { TIPOS DE } \\
\text { ÁGUAS }\end{array}$} & \multicolumn{2}{|c|}{$\begin{array}{l}\text { Bicarbonatada- } \\
\text { cloretada mista e } \\
\text { cloretada-bicarbo- } \\
\text { natada mista }\end{array}$} & \multicolumn{2}{|c|}{$\begin{array}{c}\text { Bicarbonatada } \\
\text { magnesiana }\end{array}$} & \multicolumn{2}{|c|}{$\begin{array}{c}\text { Bicarbonatada } \\
\text { sódica }\end{array}$} & \multicolumn{2}{|c|}{$\begin{array}{c}\text { Bicarbonatada } \\
\text { cálcica }\end{array}$} \\
\hline & Média & Mediana & Média & Mediana & Média & Mediana & Média & Mediana \\
\hline Turbidez (UT) & 4,59 & 0,30 & 3,67 & 2,00 & 0,69 & 0,50 & 0,98 & 0,50 \\
\hline Cor $(\mathrm{uH})$ & 7,14 & 5,00 & 19,42 & 6,50 & 3,36 & 2,50 & 3,86 & 2,50 \\
\hline $\begin{array}{c}\text { Condutividade } \\
(\mu \mathrm{Scm} / \mathrm{s})\end{array}$ & 258,21 & 258,00 & 297,56 & 300,00 & 268,57 & 255,50 & 274,28 & 263,50 \\
\hline $\mathrm{pH}$ & 6,19 & 6,25 & 7,46 & 7,63 & 8,14 & 8,20 & 7,54 & 7,66 \\
\hline Dureza $(\mathrm{mg} / \mathrm{L})$ & 98,86 & 98,46 & 103,13 & 101,90 & 100,37 & 91,04 & 107,06 & 103,95 \\
\hline $\mathrm{STD}(\mathrm{mg} / \mathrm{L})$ & 217,00 & 209,00 & 198,81 & 199,00 & 195,80 & 186,90 & 189,14 & 182,60 \\
\hline $\mathrm{SiO} 2-(\mathrm{mg} / \mathrm{L})$ & 25,08 & 31,65 & 27,81 & 28,00 & 19,55 & 21,55 & 28,21 & 32,75 \\
\hline $\mathrm{HCO} 3-(\mathrm{mg} / \mathrm{L})$ & 61,27 & 52,32 & 148,47 & 158,00 & 154,50 & 149,09 & 149,37 & 150,42 \\
\hline CO32- (mg/L) & 0,00 & 0,00 & 0,01 & 0,00 & 4,06 & 1,50 & 0,86 & 0,00 \\
\hline Cl- (mg/L) & 26,33 & 21,00 & 11,16 & 8,00 & 4,51 & 1,80 & 10,12 & 6,93 \\
\hline $\mathrm{F}-(\mathrm{mg} / \mathrm{L})$ & 0,06 & 0,01 & 0,76 & 0,24 & 0,64 & 0,33 & 0,17 & 0,00 \\
\hline PO43- (mg/L) & 0,76 & 0,11 & 1,77 & 0,02 & 2,32 & 0,01 & 0,29 & 0,00 \\
\hline SO42- $(\mathrm{mg} / \mathrm{L})$ & 0,36 & 0,50 & 9,09 & 1,20 & 8,58 & 2,45 & 4,40 & 1,00 \\
\hline NO3- (mg/L) & 47,56 & 47,74 & 7,01 & 2,87 & 0,12 & 0,02 & 5,29 & 0,80 \\
\hline $\mathrm{Ca} 2+(\mathrm{mg} / \mathrm{L})$ & 19,79 & 20,16 & 20,26 & 20,89 & 15,20 & 15,88 & 30,01 & 28,95 \\
\hline $\mathrm{Mg} 2+(\mathrm{mg} / \mathrm{L})$ & 10,02 & 9,72 & 20,06 & 18,30 & 4,19 & 3,55 & 9,17 & 8,73 \\
\hline $\mathrm{Na}+(\mathrm{mg} / \mathrm{L})$ & 15,23 & 15,00 & 12,02 & 12,30 & 42,92 & 40,15 & 14,44 & 12,30 \\
\hline $\mathrm{K}+(\mathrm{mg} / \mathrm{L})$ & 3,06 & 3,60 & 2,17 & 1,50 & 2,12 & 1,80 & 2,49 & 2,10 \\
\hline Ferro total $(\mathrm{mg} / \mathrm{L})$ & 0,24 & 0,12 & 0,58 & 0,13 & 0,36 & 0,02 & 0,25 & 0,07 \\
\hline
\end{tabular}




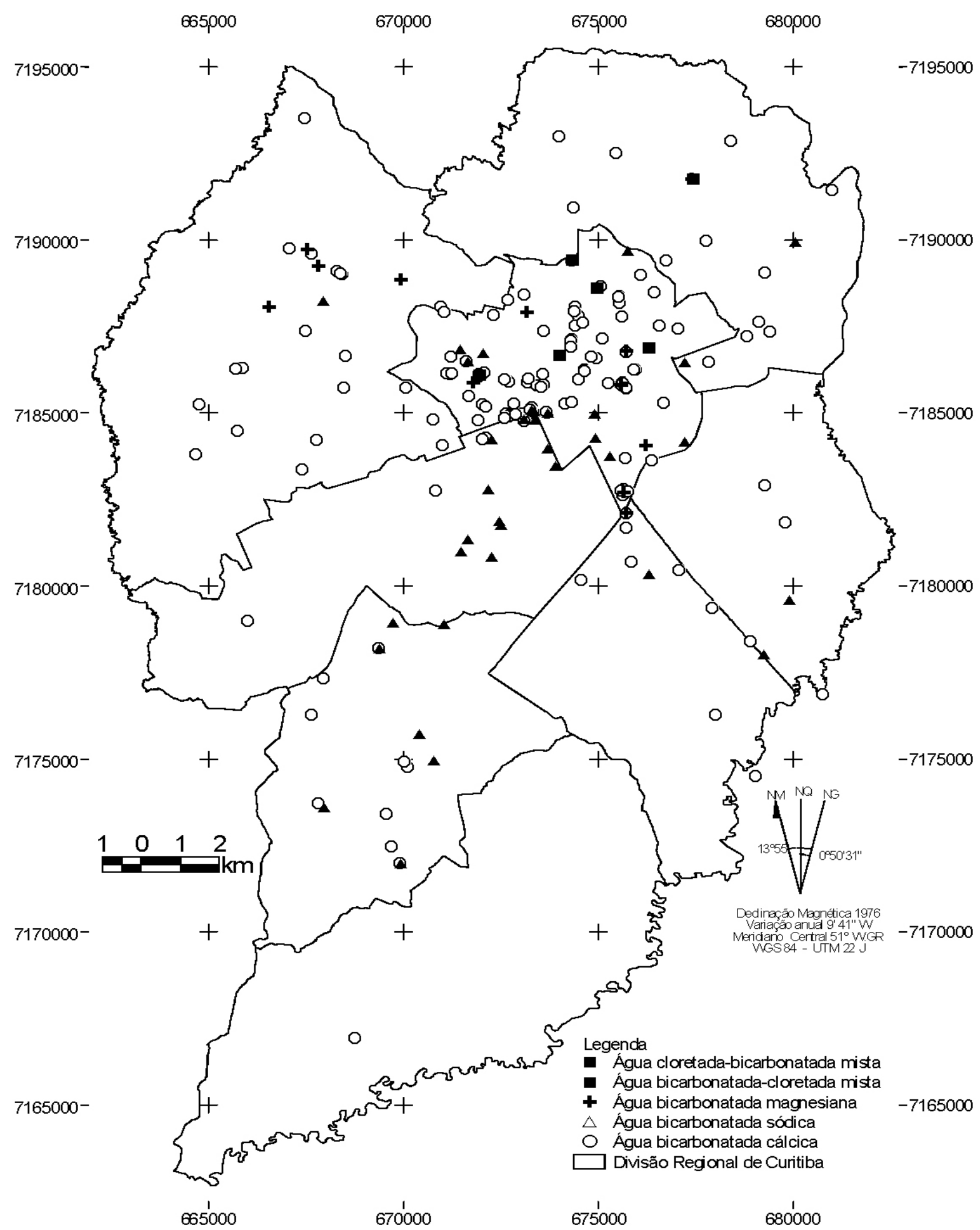

Figura 7 - Distribuição espacial dos tipos de águas: bicarbonatada cálcica, bicarbonatada sódica, bicarbonatada magnesiana, bicarbonatada-cloretada mista e cloretada-bicarbonatada mista.

Figure 7 - Spacial group classes distribution.

\section{Relação litotipo aflorante versus concentrações hidroquímicas}

Analisando os parâmetros $\mathrm{SiO}_{2}^{-}, \mathrm{HCO}_{3}^{-}$, $\mathrm{CO}_{3}^{2-}, \mathrm{Cl}^{-}, \mathrm{SO}_{4}^{2-}, \mathrm{Mg}^{2+}, \mathrm{STD}$ calculados, cor, condutância específica, alcalinidade, $\mathrm{PO}_{4}^{3-}, \mathrm{NO}_{3}^{-}$, $\mathrm{Na}^{+}$, dureza e acidez, e os relacionando com as unidades geológicas Complexo Atuba, Formação Guabirotuba e depósitos aluvionares, observa-se:
As menores concentrações dos parâmetros: $\mathrm{SiO}_{2}^{-}, \mathrm{HCO}_{3}^{-}, \mathrm{CO}_{3}^{2-}, \mathrm{Cl}^{-}, \mathrm{SO}_{4}^{2-}, \mathrm{Mg}^{2+}, \mathrm{STD}$ calculados, cor, condutância específica e alcalinidade, ocorrem em poços locados sobre o Complexo Atuba. As concentrações mais elevadas destes mesmos parâmetros ocorrem em poços localizados sobre os depósitos aluvionares (Figura $8)$. 
Nos poços localizados sobre a Formação Guabirotuba, os parâmetros $\mathrm{PO}_{4}^{3-}, \mathrm{NO}_{3}^{-}, \mathrm{Na}^{+}$, dureza e acidez apresentam valores mais elevados, quando comparados às outras unidades geológicas (Figura 9).

Análise estatística multivariada

Os dados hidroquímicos utilizados na análise estatística multivariada provêm de 166 amostras com 15 variáveis: $\mathrm{pH}, \mathrm{STD}, \mathrm{HCO}_{3}^{-}, \mathrm{CO}_{3}^{2-}, \mathrm{Cl}^{-}$,
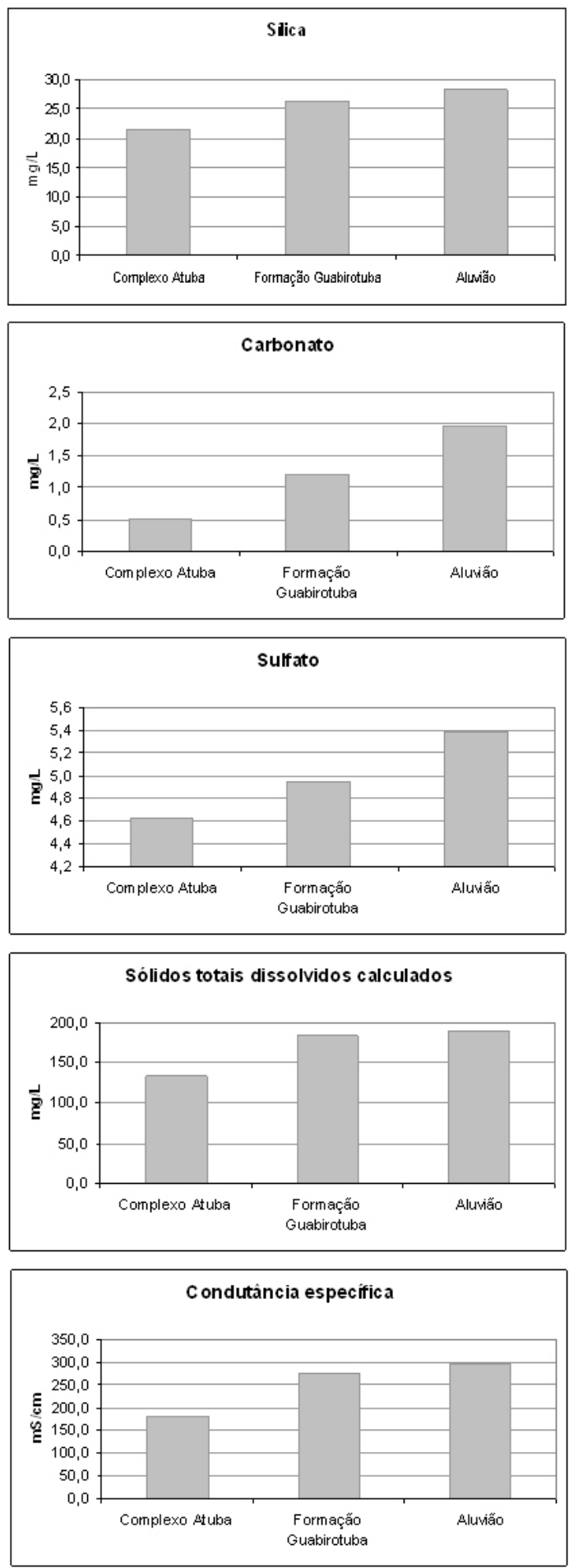

$\mathrm{F}^{-}, \mathrm{PO}_{4}^{3-}, \mathrm{SO}_{4}{ }^{2-}, \mathrm{NO}_{3}^{-}, \mathrm{SiO}_{2}^{-}, \mathrm{Ca}^{2+}, \mathrm{Mg}^{2+}, \mathrm{Na}^{+}, \mathrm{K}^{+} \mathrm{e}$ Ferro total.

Após a normalização dos dados foi calculada a matriz de covariância, que é simétrica e mostra a influência de uma variável sobre a outra (Tabela 3). Na matriz de covariância, a diagonal é ocupada pelas variâncias de cada variável que, neste caso, são todos iguais a 1 .
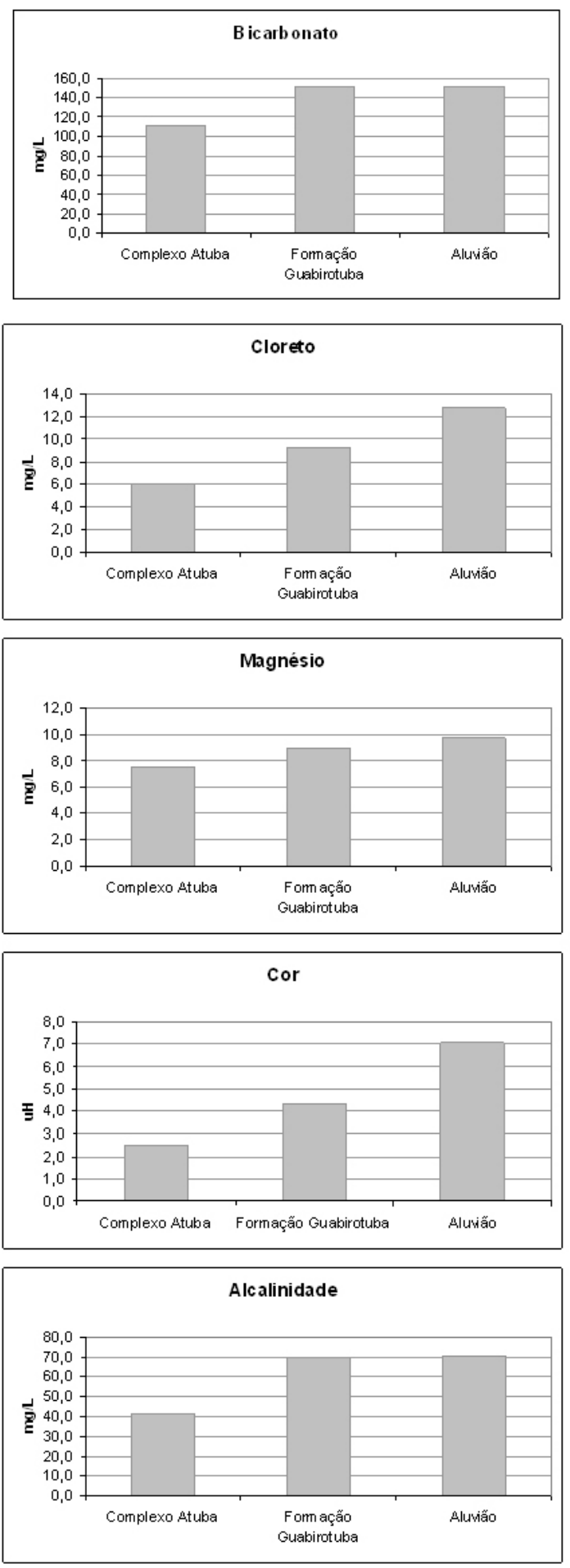

Figura 8 - Gráficos com as relações entre as concentrações físico e/ou químicas dos parâmetros sílica, bicarbonato, carbonato, cloreto, sulfato, magnésio, sólidos totais dissolvidos calculados, cor, condutância específica e alcalinidade versus a unidade geológica local.

Figure 8 - Graphics with the relations between elements concentrations and geological units. 

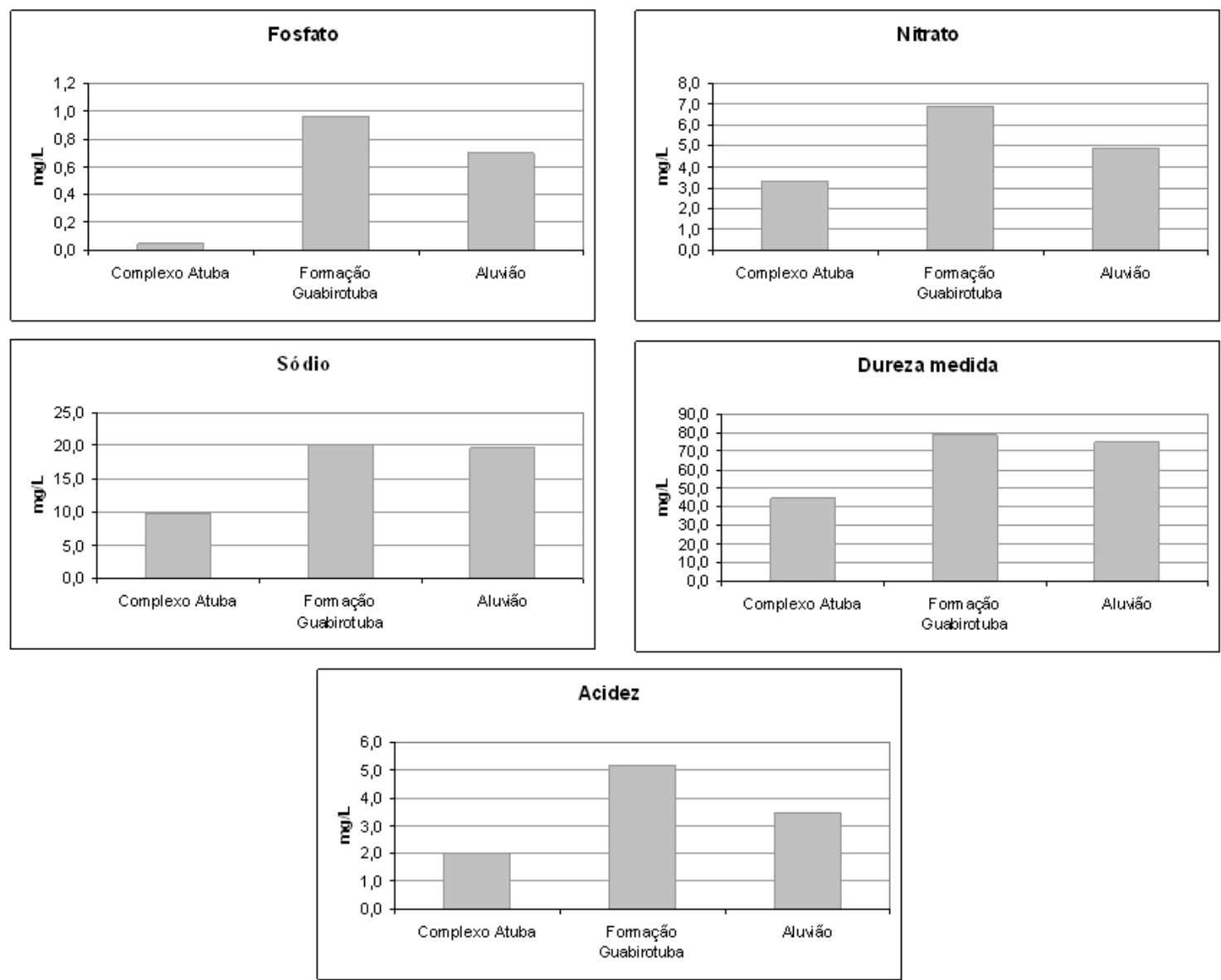

Figura 9 - Gráficos com as relações entre as concentrações físico-químicas dos parâmetros fosfato, nitrato, sódio, dureza medida e acidez, versus a unidade geológica local.

Figure 9 - Graphics with the relations between elements concentrations and geological units.

Tabela 3 - Matriz de covariância das variáveis avaliadas.

Table 3 - Covariance matrix.

\begin{tabular}{|c|c|c|c|c|c|c|c|c|c|c|c|c|c|c|c|}
\hline & pH & STD & SiO2- & ICO3- & CO3- & Cl- & F- & & & NO3- & Ca2+ & Mg2+ & $\mathrm{Na}+$ & $\mathbf{K}+$ & $\begin{array}{c}\text { Ferro } \\
\text { total }\end{array}$ \\
\hline $\mathbf{p H}$ & 1,00 & & & & & 025 & & & & & & & & & 0,07 \\
\hline STD & 0,15 & 1,00 & 0,44 & & & 0,09 & 0,25 & & & & & & 0,12 & $-0,09$ & 13 \\
\hline SiO2- & 0,13 & 0,44 & 1,00 & 0,00 & $-0,13$ & 0,13 & 0,12 & 0,09 & $-0,04$ & 0,15 & 0,18 & 0,1 & $-0,21$ & $-0,13$ & 0,00 \\
\hline HCO3- & 0,00 & 0,18 & 0,00 & 1,00 & 0,14 & 0,12 & $-0,07$ & 0,07 & 0,09 & $-0,28$ & 0,65 & 0,5 & 0,27 &, 05 & 0,03 \\
\hline CO3- & 0,21 & 0,05 & $-0,13$ & 0,14 & 1,00 & $-0,06$ & $-0,03$ & $-0,07$ & 0,10 & $-0,19$ & $-0,15$ & -0 , & 0,54 & 0,04 & $-0,04$ \\
\hline Cl- & $-0,25$ & 0,09 & 0,13 & 0,12 & $-0,06$ & 1,00 & $-0,19$ & $-0,05$ & $-0,08$ & 0,55 & 0,51 & 0,48 & $-0,18$ & 0,06 & $-0,09$ \\
\hline F- & 0,09 & 0,25 & 0,12 & $-0,07$ & $-0,03$ & $-0,19$ & 1,00 & 0,13 & 0,29 & $-0,09$ & $-0,24$ & $-0,16$ & 0,31 & $-0,09$ & 0,02 \\
\hline PO43- & 0,01 & 0,22 & 0,09 & 0,07 & $-0,07$ & $-0,05$ & 0,13 & 1,00 & $-0,07$ & $-0,01$ & 0,04 & $-0,02$ & 0,23 & 0,00 & 0,74 \\
\hline SO42- & 0,14 & 0,12 & $-0,04$ & 0,09 & 0,10 & $-0,08$ & 0,29 & $-0,07$ & 1,00 & $-0,15$ & $-0,02$ & 0,03 & 0,28 & $-0,06$ & $-0,09$ \\
\hline NO3- & $-0,28$ & 0,28 & 0,15 & $-0,28$ & $-0,19$ & 0,55 & $-0,09$ & $-0,01$ & $-0,15$ & 1,00 & 0,16 & 0,25 & $-0,26$ & 0,09 & $-0,04$ \\
\hline $\mathrm{Ca} 2+$ & $-0,26$ & 0,19 & 0,18 & & $-0,15$ & 0,51 & $-0,24$ & 0,04 & $-0,02$ & 0,16 & 1,00 & 0,54 & $-0,33$ & 0,02 & $-0,03$ \\
\hline Mg2+ & $-0,22$ & 0,20 & & & $-0,18$ & 0,48 & $-0,16$ & $-0,02$ & & & & 1,00 & $-0,36$ & 0,09 & $-0,03$ \\
\hline $\mathrm{Na}+$ & 0,30 & 0,12 & $-0,21$ & 0,27 & 0,54 & $-0,18$ & 0,31 & 0,23 & 0,28 & $-0,26$ & $-0,33$ & $-0,36$ & 1,00 & $-0,05$ & 0,14 \\
\hline $\mathbf{K}+$ & $-0,10$ & $-0,09$ & $-0,13$ & 0,05 & 0,04 & 0,06 & $-0,09$ & 0,00 & $-0,06$ & 0,09 & 0,02 & 0,09 & $-0,05$ & 1,00 & 0,08 \\
\hline $\begin{array}{c}\text { Ferro } \\
\text { total }\end{array}$ & 0,07 & 0,13 & 0,00 & 0,03 & $-0,04$ & $-0,09$ & 0,02 & 0,74 & $-0,09$ & $-0,04$ & $-0,03$ & $-0,03$ & 0,14 & 0,08 & 1,00 \\
\hline
\end{tabular}


Com os autovetores da matriz de covariância foram calculados os 6 componentes principais que são responsáveis por $73 \%$ da variabilidade total do sistema (Tabela 4 ).

Tabela 4 - Contribuição de cada componente principal para a variabilidade global.

Table 4 - Contribution of each component for global variability.

\begin{tabular}{|c|c|c|c|}
\hline 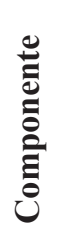 & 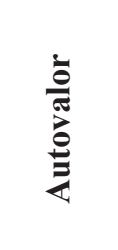 & 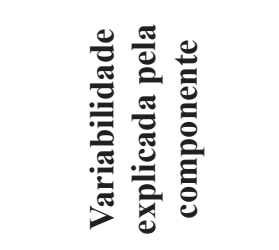 & 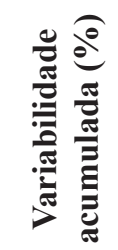 \\
\hline 1 & 3,1028 & $3,102 / 15=20,68 \%$ & 20,6853 \\
\hline 2 & 2,1840 & $2,184 / 15=14,55 \%$ & 35,2451 \\
\hline 3 & 1,8033 & $1,803 / 15=12,02 \%$ & 47,2673 \\
\hline 4 & 1,6072 & $1,607 / 15=10,71 \%$ & 57,9816 \\
\hline 5 & 1,2245 & $1,224 / 15=8,16 \%$ & 66,1452 \\
\hline 6 & 1,0877 & $1,087 / 15=7,25 \%$ & 73,3967 \\
\hline
\end{tabular}

A partir dos loading factors, que são os coeficientes dos vetores unitários que dão as direções das componentes, são indicadas as variáveis que possuem maior influência nos seis componentes principais (Tabela 5).

Tabela 5- Loading factors das variáveis que compõem os seis componentes principais (Fator 1 a 6 ).

Table 5 - Loading factors for 6 variables of principal components.

\begin{tabular}{|c|c|c|c|c|c|c|}
\hline & Fator 1 & Fator 2 & Fator 3 & Fator 4 & Fator 5 & Fator 6 \\
\hline $\mathrm{pH}$ & $-0,1751$ & 0,4599 & 0,0059 & $-0,4824$ & $-0,3471$ & 0,0571 \\
\hline STD & 0,1876 & 0,1820 & 0,2348 & $-0,6301$ & 0,3516 & $-0,2866$ \\
\hline $\mathrm{SiO}_{2}^{-}$ & 0,1010 & $-0,1470$ & 0,0476 & $-0,8005$ & 0,1743 & 0,0301 \\
\hline $\mathrm{HCO}_{3}^{-}$ & 0,8863 & 0,2597 & 0,0807 & 0,0220 & $-0,2300$ & $-0,0749$ \\
\hline $\mathrm{CO}_{3}{ }^{2-}$ & $-0,0226$ & 0,8733 & $-0,0989$ & 0,0779 & 0,0006 & 0,0499 \\
\hline $\mathrm{Cl}^{-}$ & 0,4089 & $-0,0143$ & $-0,1021$ & 0,0340 & 0,7149 & 0,1327 \\
\hline$F^{-}$ & $-0,2130$ & $-0,0197$ & 0,1315 & $-0,1774$ & $-0,0248$ & $-0,7887$ \\
\hline $\mathbf{P O}_{4}{ }^{3-}$ & 0,0293 & 0,0080 & 0,9237 & $-0,0508$ & $-0,0011$ & $-0,0528$ \\
\hline $\mathrm{SO}_{4}^{2-}$ & 0,1199 & 0,1270 & $-0,1635$ & 0,0200 & $-0,1080$ & $-0,7495$ \\
\hline $\mathrm{NO}_{3}^{-}$ & $-0,0702$ & $-0,1610$ & $-0,0028$ & $-0,0694$ & 0,9035 & 0,0632 \\
\hline $\mathrm{Ca}^{2+}$ & 0,8567 & $-0,1771$ & $-0,0011$ & $-0,0677$ & 0,1762 & 0,1205 \\
\hline $\mathbf{M g}^{2+}$ & 0,7475 & $-0,2279$ & $-0,0403$ & $-0,0545$ & 0,2866 & 0,0161 \\
\hline $\mathrm{Na}^{+}$ & $-0,0976$ & 0,7726 & 0,2133 & 0,0930 & $-0,1580$ & $-0,3877$ \\
\hline $\mathbf{K}^{+}$ & 0,0513 & 0,0947 & 0,1236 & 0,4709 & 0,2497 & 0,0870 \\
\hline Ferro total & $-0,0143$ & 0,0143 & 0,9113 & 0,0259 & $-0,0490$ & 0,0761 \\
\hline
\end{tabular}

OFator principal 1, discriminado pelas variáveis $\mathrm{HCO}_{3}^{-}, \mathrm{Ca}^{2+} \mathrm{e} \mathrm{Mg}^{2+}$, foi responsável por $20,68 \%$ da variância total. O Fator 2 foi determinado pelos teores de $\mathrm{CO}_{3}{ }^{2-}$ e $\mathrm{Na}^{+}$, sendo responsáveis por $14,55 \%$ variância global. No Fator 3 exercem maior peso $\mathrm{PO}_{4}^{3-}$ e ferro total, responsáveis juntos por $12,02 \%$ da variância total. O Fator 4, determinado apenas pela $\mathrm{SiO}_{2}$ - foi responsável por $10,71 \%$ da variância total. Os ânions $\mathrm{NO}_{3}^{-} \mathrm{e} \mathrm{Cl}^{-}$ exercem maior peso no quinto fator, responsável por $8,16 \%$ da variância total e, $\mathrm{F}^{-}$e $\mathrm{SO}_{4}^{2-}$ exercem maior peso no Fator 6, o qual é responsável por $7,25 \%$ da variância total.

A partir da análise estatística multivariada 
foi possível verificar a existência da ação antropogênica nas águas, visto que os íons $\mathrm{NO}_{3}^{-}$ e $\mathrm{Cl}^{-}$apresentaram similaridades entre si, a ponto de formar juntos, a quinta componente principal, denominada de Fator 5, a qual explicou 8,16\% da variância total do sistema.

A correlação positiva entre o $\mathrm{Cl}^{-}$e $\mathrm{NO}_{3}^{-}$, especialmente nas proximidades da regional da matriz de Curitiba, permite identificar a degradação na qualidade destas águas pela ação antrópica e, como não existe fonte natural para o nitrato acredita-se que este elemento tenha sido introduzido no sistema aqüífero cristalino através da infiltração de efluentes domésticos.

\section{Conclusões}

Os laudos analíticos provenientes de 227 análises físico-químicas, de poços tubulares profundos situados em Curitiba, classificaram quatro tipos principais de águas:

As águas bicarbonatadas cálcicas foram determinadas em $73,5 \%$ dos poços, portanto, a tipologia predominante do aqüífero fraturado (Complexo Atuba). Nestas águas a concentração mediana do $\mathrm{HCO}_{3}{ }^{-}$é $150,42 \mathrm{mg} / \mathrm{L}, \mathrm{Cl}^{-}=6,96 \mathrm{mg} / \mathrm{L}$, $\mathrm{NO}_{3}=0,8 \mathrm{mg} / \mathrm{L}, \quad \mathrm{Ca}^{2+}=28,95 \mathrm{mg} / \mathrm{L}, \quad \mathrm{Mg}^{2+}$ $=8,73 \mathrm{mg} / \mathrm{L}, \mathrm{Na}^{+}=12,30 \mathrm{mg} / \mathrm{L}$ e ferro total é $0,07 \mathrm{mg} / \mathrm{L}$.

As águas bicarbonatadas sódicas foram determinadas em $16,7 \%$ dos poços. Nestas águas a concentração mediana do $\mathrm{HCO}_{3}^{-}$é $149,09 \mathrm{mg} / \mathrm{L}$, $\mathrm{Cl}^{-}=1,8 \mathrm{mg} / \mathrm{L}, \mathrm{NO}_{3}{ }^{-}=0,8 \mathrm{mg} / \mathrm{L}, \mathrm{Ca}^{2+}=15,88 \mathrm{mg} / \mathrm{L}$, $\mathrm{Mg}^{2+}=3,55 \mathrm{mg} / \mathrm{L}, \mathrm{Na}^{+}=40,15 \mathrm{mg} / \mathrm{L}$ e ferro total é $0,02 \mathrm{mg} / \mathrm{L}$.

As águas bicarbonatadas magnesianas estão presentes em $6,6 \%$ dos poços. Neste tipo de água a concentração mediana do $\mathrm{HCO}_{3}^{-}$é $158 \mathrm{mg} / \mathrm{L}$, $\mathrm{Cl}^{-}=8 \mathrm{mg} / \mathrm{L}, \mathrm{NO}_{3}{ }^{-}=2,87 \mathrm{mg} / \mathrm{L}, \mathrm{Ca}^{2+}=20,89 \mathrm{mg} / \mathrm{L}$, $\mathrm{Mg}^{2+}=18,30 \mathrm{mg} / \mathrm{L}, \mathrm{Na}^{+}=12,30 \mathrm{mg} / \mathrm{L}$ e ferro total é $0,13 \mathrm{mg} / \mathrm{L}$.

As bicarbonatadas-cloretadas mistas e cloretada-bicarbonatada magnesiana-sódica mista foram determinadas em 3\% dos poços. Nestas águas a concentração mediana do $\mathrm{HCO}_{3}{ }^{-}$é $52,32 \mathrm{mg} / \mathrm{L}, \mathrm{Cl}^{-}=21 \mathrm{mg} / \mathrm{L}, \mathrm{NO}_{3}^{-}=47,74 \mathrm{mg} /, \mathrm{Ca}^{2+}$ $=20,16 \mathrm{mg} / \mathrm{L}, \mathrm{Mg}^{2+}=9,72 \mathrm{mg} / \mathrm{L}, \mathrm{Na}^{+}=15 \mathrm{mg} / \mathrm{L} \mathrm{e}$ ferro total é $0,12 \mathrm{mg} / \mathrm{L}$.

Predominam no município de Curitiba poços tubulares locados sobre a Formação Guabirotuba, seguido por poços situados sobre os aluviões e Embasamento (Complexo Atuba). Ressalta-se que o aqǘf́ro mais explotado corresponde ao Complexo Atuba.

A heterogeneidade litológica reflete em heterogeneidade hidroquímica visto que, as concentrações de compostos como $\mathrm{SiO}_{2}^{-}, \mathrm{HCO}_{3}^{-}$, $\mathrm{CO}_{3}^{-}, \mathrm{Cl}^{-}, \mathrm{SO}_{4}^{2-}, \mathrm{Mg}^{2+}$, STD calculados, cor, condutância específica, alcalinidade, $\mathrm{PO}_{4}^{3-}, \mathrm{NO}_{3}^{-}$, $\mathrm{Na}^{+}$, dureza calculada e acidez, variam conforme o tipo de rocha aflorante no Município.

Os poços situados no Complexo Atuba, em comparação aos poços locados sobre a Formação Guabirotuba e sobre sedimentos aluvionares, apresentam as menores concentrações de $\mathrm{SiO}_{2}^{-}$, $\mathrm{HCO}_{3}^{-}, \mathrm{CO}_{3}^{-}, \mathrm{Cl}^{-}, \mathrm{SO}_{4}^{2-}, \mathrm{Mg}^{2}$, STD calculados, cor, condutância específica e alcalinidade. Os poços localizados sobre os sedimentos da Formação Guabirotuba possuem valores intermediários e, os poços construídos em terrenos aluvionares apresentam os valores mais elevados para os mesmos parâmetros.

Em contrapartida, poços localizados sobre os sedimentos da Formação Guabirotuba, seguidos respectivamente pelos poços locados sobre os aluviões e sobre Complexo Atuba, apresentaram as concentrações médias mais elevadas de $\mathrm{PO}_{4}^{3-}$, $\mathrm{NO}_{3}^{-}, \mathrm{Na}^{+}$, dureza calculada e acidez.

A análise estatística multivariada determinou seis componentes principais que explicam $73 \%$ da variabilidade do sistema. Dentre elas, o Fator principal 1, discriminado pelas variáveis $\mathrm{HCO}_{3}{ }^{-}$, $\mathrm{Ca}^{2+}$ e $\mathrm{Mg}^{2+}$, foi responsável por $20,68 \%$ da variância total. $\mathrm{O}$ Fator 2 foi determinado pelos teores de $\mathrm{CO}_{3}^{2-}$ e $\mathrm{Na}^{+}$, sendo responsáveis por 14,55\% variância global. No Fator 3 exercem maior peso $\mathrm{PO}_{4}^{3-}$ e ferro total, responsáveis juntos por $12,02 \%$ da variância total. O Fator 4, determinado apenas pela $\mathrm{SiO}_{2}^{-}$foi responsável por $10,71 \%$ da variância total. Os ânions $\mathrm{NO}_{3}^{-} \mathrm{e} \mathrm{Cl}^{-}$ exercem maior peso no quinto fator, responsável por $8,16 \%$ da variância total e, $\mathrm{F}^{-}$e $\mathrm{SO}_{4}^{2-}$ exercem maior peso no Fator 6, o qual é responsável por $7,25 \%$ da variância total.

A partir da análise estatística multivariada foi possível verificar a existência da ação antropogênica nas águas, visto que os íons $\mathrm{Cl}^{-} \mathrm{e}$ $\mathrm{NO}_{3}^{-}$apresentaram similaridades entre si a ponto de formar juntos, a quinta componente principal, denominada de Fator 5, a qual explicou 8,16\% da variância total do sistema.

A correlação positiva entre o $\mathrm{Cl}^{-}$e $\mathrm{NO}_{3}^{-}$, especialmente nas proximidades da regional da matriz de Curitiba, permite identificar a degradação na qualidade destas águas pela ação antrópica. Como não existe fonte natural para o nitrato, acredita-se que este composto químico foi introduzido no sistema através da infiltração de efluentes domésticos até o aqüífero cristalino.

Ainda que a maior parte dos poços estudados apresentem parâmetros que não ultrapassam os 
limites máximos estabelecidos pela Portaria ${ }^{\circ} 518$ do Ministério da Saúde, existem poços tubulares profundos que contêm teores $\mathrm{de}^{-}{ }^{-} \mathrm{NO}_{3}^{-}$, ferro total, $\mathrm{pH}$ e turbidez que não se enquadram nos limites máximos permitido para fins de potabilidade.
Para tanto, torna-se imprescindível uma nova campanha de amostragem para avaliar o estado atual da qualidade deste importante manancial subterrâneo e, estabelecer medidas de proteção e gerenciamento para o mesmo.

\section{REFERÊNCIAS}

BECKER， R. D. 1982. Distribuição dos sedimentos cenozóicos na região metropolitana de Curitiba e sua relação com a estrutura geológica e morfológica regional. Tese (Doutorado) Pós Graduação em Geociências, Universidade Federal do Rio Grande do Sul.

BIGARELLA J. J.; SALAMUNI R. 1959. Notas complementares à Planta Geológica da cidade de Curitiba e arredores. IBPT- Instituto de Biologia e Pesquisas Tecnológicas, Curitiba, n. ${ }^{\circ} 40$, p. 3-14.

BRASIL. 2004. Ministério da Saúde. Portaria $\mathrm{n}^{\mathrm{o}} 518$ de 25 de março de 2004. Estabelece normas e o padrão de potabilidade da água destinada ao consumo humano. Diário Oficial da União, Brasília, v. 59, p. 266-270, 26 mar. 2004, Seção 1.

CHAVEZ-KUS, L. 2003. Análise da tectônica rúptil em rochas do embasamento da Bacia de Curitiba com vistas à determinação de áreas favoráveis à exploração de água subterrânea. Curitiba,214f.Dissertação(MestradoemGeologia) - Setor de Ciências da terra, Universidade Federal do Paraná.

PIPER, A.M. A graphic procedure in the geochemical interpretation of water-analyses. Transactions of the American Geophysical Union - 1944. Washington (DC), Part VI, p. 914928, May/1945.

ROSA FILHO, E. F.; LISBOA A. A. ; SCHOENAU O. 1996. Abastecimento de água de Curitiba -Situação atual e proposta de solução - In: Workshop Internacional Ampliações dos Sistemas de Abastecimento de Água Potável nas Grades Metrópoles, 1., Belo Horizonte. Atas... Belo Horizonte.

ROSA FILHO, E. F.; UDLUFT, P.; HEINRICHS, G. 1998.Determinação da Recarga das Camadas Aquíferas da Formação Guabirotuba na Bacia Hidrográfica do Iraí. Boletim Paranaense de Geociências. São Paulo ,v.17, p.10 - 27.

ROSA FILHO E. F.; HINDI, E. C.; GIUSTI, D. A.; NADAL, C. A. 1998. Utilização das Águas
Subterrâneas no Abastecimento Público das Cidades Paranaenses. Boletim Paranaense de Geociências. Curitiba: , v.46, p. 13 - 23.

ROSA FILHO, E. F.; BITTENCOURT, A. V. L.; HINDI, E. C. 1998. Hidroquímica da Formação Guabirotuba na Porção Oriental da Bacia de Curitiba. Boletim Paranaense de Geociências. Curitiba, $n^{\circ} .46$, p. $131-139$.

ROSA FILHO E. F.; HINDI E. C.; LUCENA L. R. F. 2002. Os Aqüíferos que contribuem no abastecimento da cidade de Curitiba. Revista Águas Subterrâneas. n. ${ }^{\circ} 16$.

SALAMUNI E.; SALAMUNI R.; EBERTH H. D. 1999. Contribuição à geologia da Bacia Sedimentar de Curitiba (PR). Boletim Paranaense de Geociências, Universidade Federal do Paraná, v. 47.

SALAMUNI, E. 2005. Aspectos da Tectônica cenozóica e condicionamento do relevo da Serra do Mar e Planalto de Curitiba. Programa de excursão temática. Curitiba, X-SNET Simpósio Nacional de Estudos Tectônicos e IV-ST Internacional Symposium on Tectonics. Curitiba, jun/ 2005.

SEIXAS FILHO, C.; FERNANDES, L. R.; CARVALHO, F. B. 2006. Tutorial PCA- Uso de uma técnica de análise multivariada para detecção antecipada de comportamento anormal em controle de processos. Brasil Intech. Curitiba, $\mathrm{n}^{\circ}$ 85, p. 32-41.

SIGA JR., O.; BASEI, M. A. S.; REIS NETO, J. M.; MACHIAVELLI, A.; HARARA, O. M.1995. O Complexo Atuba: Um cinturão paleoproterozóico intensamente retrabalhado no neoproterozóico. Boletim do Instituto de Geociências da Universidade de São Paulo, Série Científica, v.26, p.69-98.

SIGA JR. O. 1995. Domínios tectônicos da região sudeste do Paraná e nordeste de Santa Catarina. Geocronologia e evolução crustal. São Paulo, 212p. (Tese de Doutorado), Instituto de Geociências, Universidade de São Paulo.

SUREHMA. 1989. Localização dos poços de Curitiba. Mapa preliminar. Escala 1: 25000. 
